\title{
O sistema financeiro atual trava o desenvolvimento econômico
}

LADISLAU DOWBOR ${ }^{I}$

"Não havia como escapar a essa dura realidade: o sistema econômico só funcionava de forma regular quando a remuneração do capital atingia determinados níveis. Essa constatação nos permite entender outro ponto intrigante da dinâmica da economia brasileira: suas extravagantes taxas de juros.”

(Celso Furtado)

"Os bancos deveriam voltar a fazer o que faziam quando foram criados: oferecer um local seguro para as poupanças e capital a negócios que pretendem se desenvolver.”

(J. C. Polychroniu)

$\mathrm{U}$ M DEBATE fundamental pede passagem: a esterilização dos recursos do país através do sistema de intermediação financeira, que drena em volumes impressionantes recursos que deveriam servir ao fomento produtivo e ao desenvolvimento econômico. Os números são bastante claros, e conhecidos, e basta juntá-los para entender o impacto.

\section{O crediário}

Comecemos pelas taxas de juros ao tomador final, pessoa física, praticadas no comércio, os chamados crediários. A Associação Nacional de Executivos de Finanças, Administração e Contabilidade (Anefac) traz os dados de junho 2014.

Antes de tudo, uma nota metodológica: os juros são quase sempre apresentados, no Brasil, como "taxa mês", como na primeira coluna do Quadro 1. É tecnicamente certo, mas comercial e eticamente errado. É uma forma de confundir os tomadores de crédito, pois ninguém consegue calcular mentalmente juros compostos. O que é usado mundialmente é o juro anual que resulta. $\mathrm{O}$ Banco Itaú, por exemplo, apresenta no seu site as taxas de juros apenas no formato mensal, pois ao ano apareceriam como são, extorsivos. Na foto da Figura 1 vemos a TV oferecida com taxa de juros de 6,87\% ao mês, e aparece em letras miúdas, por obrigação legal, o juro real ao ano de $122 \%$, literalmente um assalto.

A média de juros praticadas nos crediários, de 72,33\%, significa simplesmente que esse tipo de comércio, em vez de prestar decentemente serviços comerciais, se transformou essencialmente num banco. Aproveita o fato de as pessoas não entenderem de cálculo financeiro, e de disponibilizarem de pouco dinheiro à vista, para as extorquir. Aqui, o produtor de "Artigos do Lar", ao cobrar juros de $104,89 \%$ sobre os produtos, trava a demanda, pois ficará represada 
por doze ou 24 meses enquanto se pagam as prestações, e trava o produtor, que recebe muito pouco pelo produto. É o que temos qualificado de economia do pedágio. Ironicamente, as lojas dizem que "facilitam". No conjunto do processo, a capacidade de compra do consumidor é dividida por dois, e a capacidade de reinvestimento do produtor estanca.

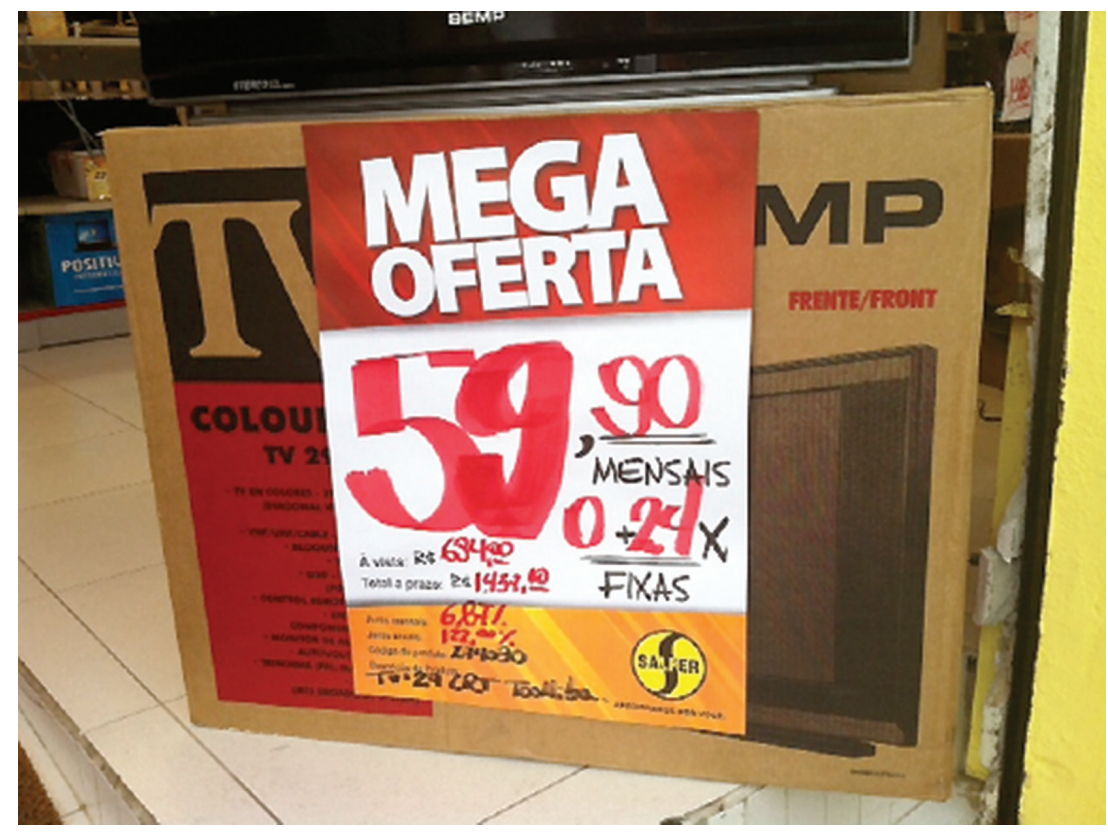

Figura l - Loja em Joinville: A prestação que "cabe no bolso" está em letras grandes. Colocam o valor final e juros bem pequenos: paga-se mais do dobro, juros de $122 \%$. Permite comprar hoje, mas trava-se a capacidade de consumo por dois anos. O produtor recebe pouco, e pouco poderá investir. E o consumidor pode comprar pouco, pelo peso dos juros. É a chamada economia do pedágio, que trava o sistema produtivo, tanto do lado do produtor como do lado do consumidor, em proveito do intermediário. Rede semelhante na Europa, MidiaMarkt, cobra 13,3\% ao ano. Uma compra de 600 euros em dezoito meses custa um total final de 699 euros. E ganham bem com isso.

\section{Os juros para pessoa física}

Os consumidores não se limitam a comprar pelo crediário, cuja taxa média de 72,33\% aparece reproduzida no Quadro 2 na primeira linha. Usam também cartão de crédito e outras modalidades de mecanismos financeiros pouco compreendidas pela imensa maioria dos consumidores.

Tomando os dados de junho 2014, constatamos que os intermediários financeiros cobram também $238,67 \%$ no cartão de crédito; $159,76 \%$ no cheque especial; $23,58 \%$ na compra de automóveis. Os empréstimos pessoais custam na média $50,23 \%$ nos bancos e $134,22 \%$ nas financeiras. Estamos deixando aqui de lado a agiotagem de rua que ultrapassa os $300 \%$. 
Quadro 1 - Comportamento das taxas de juros do crediário por setor

\begin{tabular}{l|c|c|c|c|c|c}
\hline \multirow{2}{*}{ Setores } & \multicolumn{2}{|c|}{ Maio 2014} & \multicolumn{2}{c|}{ Junho 2014} & \multirow{2}{*}{$\begin{array}{c}\text { Variação } \\
\%\end{array}$} & $\begin{array}{c}\text { Var. Pontos } \\
\text { Percentuais } \\
\text { ao Mês }\end{array}$ \\
\cline { 2 - 5 } & Taxa Mês & Taxa Ano & Taxa Mês & Taxa Ano & $0,80 \%$ & 0.02 \\
\hline Gdes Redes & $2,49 \%$ & $34,33 \%$ & $2,51 \%$ & $34,65 \%$ & $0,80 \%$ & 0.03 \\
\hline Med. Redes & $4,80 \%$ & $75,52 \%$ & $4,83 \%$ & $76,13 \%$ & $0,63 \%$ & 0.04 \\
\hline Peq. Redes & $5,41 \%$ & $88,18 \%$ & $5,45 \%$ & $89,04 \%$ & $0,74 \%$ & 0.01 \\
\hline Emp. Turismo & $3,74 \%$ & $55,37 \%$ & $3,75 \%$ & $55,55 \%$ & $0,26 \%$ & 0.02 \\
\hline Art. do Lar & $6,14 \%$ & $104,43 \%$ & $6,16 \%$ & $104,89 \%$ & $0,33 \%$ & 0.04 \\
\hline Ele Eletron. & $4,60 \%$ & $71,55 \%$ & $4,64 \%$ & $72,33 \%$ & $0,87 \%$ & 0.01 \\
\hline Importados & $5,23 \%$ & $84,34 \%$ & $5,24 \%$ & $84,57 \%$ & $0,19 \%$ & -0.02 \\
\hline Veículos & $1,80 \%$ & $23,87 \%$ & $1,78 \%$ & $23,58 \%$ & $-1,11 \%$ & 0.03 \\
\hline Art. Ginástica & $6,49 \%$ & $112,67 \%$ & $6,52 \%$ & $113,39 \%$ & $0,46 \%$ & 0.03 \\
\hline Informática & $4,43 \%$ & $66,69 \%$ & $4,38 \%$ & $67,27 \%$ & $0.69 \%$ & 0.04 \\
\hline Celulares & $4,04 \%$ & $60,84 \%$ & $4,08 \%$ & $61,59 \%$ & $0.99 \%$ & 0.03 \\
\hline Decoração & $6,30 \%$ & $108,16 \%$ & $6,33 \%$ & $108,87 \%$ & $0,48 \%$ & 0.02 \\
\hline Média Geral & $4,62 \%$ & $71,94 \%$ & $4,64 \%$ & $72,33 \%$ & $0,43 \%$ & \\
\hline
\end{tabular}

Fonte: Anefac, 2014. (Disponívelem:<http://www.anefac.com.br/uploads/arquivos/201471515311 4381.pdf>).

Quadro 2 - Taxa de juros para pessoa física

\begin{tabular}{|c|c|c|c|c|c|c|}
\hline \multirow{3}{*}{$\begin{array}{l}\text { Linha de } \\
\text { Crédito }\end{array}$} & \multirow{2}{*}{\multicolumn{2}{|c|}{ Maio 2014}} & \multirow{2}{*}{\multicolumn{2}{|c|}{ Junho 2014}} & \multirow{3}{*}{$\begin{array}{c}\text { Variação } \\
\%\end{array}$} & \multirow{3}{*}{$\begin{array}{l}\text { Var. Pontos } \\
\text { Percentuais } \\
\text { ao Mês }\end{array}$} \\
\hline & & & & & & \\
\hline & Taxa Mês & Taxa Ano & Taxa Mês & Taxa Ano & & \\
\hline Juros comércio & $4,62 \%$ & $71,94 \%$ & $4,64 \%$ & $72,33 \%$ & $0,43 \%$ & 0,02 \\
\hline Cartão de crédito & $10,52 \%$ & $232,12 \%$ & $10,70 \%$ & $238,67 \%$ & $1,71 \%$ & 0,18 \\
\hline Cheque especial & $8,22 \%$ & $158,04 \%$ & $8,28 \%$ & $159,76 \%$ & $0,73 \%$ & 0,06 \\
\hline $\begin{array}{l}\text { CDC - Bancos - } \\
\text { financiamento de } \\
\text { automóveis }\end{array}$ & $1,80 \%$ & $23,87 \%$ & $1,78 \%$ & $23,58 \%$ & $-1,11 \%$ & $-0,02$ \\
\hline $\begin{array}{l}\text { Empréstimo } \\
\text { pessoal- bancos }\end{array}$ & $3,41 \%$ & $49,54 \%$ & $3,45 \%$ & $50,23 \%$ & $1,17 \%$ & 0,04 \\
\hline $\begin{array}{l}\text { Empréstimo } \\
\text { pessoal-financeiras }\end{array}$ & $7,29 \%$ & $132,65 \%$ & $7,35 \%$ & $134,22 \%$ & $0,82 \%$ & 0,06 \\
\hline Taxa Média & $5,58 \%$ & $100,76 \%$ & $6,03 \%$ & $101,90 \%$ & $0,84 \%$ & 0,05 \\
\hline
\end{tabular}

Fonte: Anefac, 2014. Disponível em: <http://www.anefac.com.br/uploads/arquivos/2014715153 114381.pdf>.

Note-se que a Associação Brasileira das Empresas de Cartões de Crédito e Serviços (Abecs) considera que o juro médio sobre o cartão é de $280 \%$, portanto bem acima da avaliação da Anefac. A Abecs considera que 50,1\% do crédito para 
consumo é feito no cartão; $23,5 \%$ no crédito consignado; $13,1 \%$ no crediário de veículos; e 13,3\% “outros”. Trata-se, no caso dos cartões, de cerca de 170 bilhões de reais.

É importante lembrar que mesmo sem entrar no crédito do cartão, tipicamente uma loja tem de pagar cerca de $5 \%$ do valor das compras ao banco, além do aluguel da máquina. Esses $5 \%$ podem ser menos para grandes lojas com capacidade de negociação com o sistema financeiro, mas de toda forma trata-se de um gigantesco imposto privado sobre a metade do crédito de consumo, reduzindo drasticamente a capacidade de compra do consumidor. A tabela da Abecs que corresponde ao total de transações de 2014 até fim de setembro é de 361 bilhões de reais. Os juros aplicados variam, mas podemos imaginar o volume de recursos apropriados sobre esse montante, pedágio que tira recursos da economia real para o sistema de intermediação financeira (<http://www.abecs. org.br/indicadores-de-mercado>).

A Abecs considera que esta carteira “está sendo responsável por fomentar o crédito ao consumidor no país". É uma forma positiva de apresentar o problema, mas fomenta-se o crédito, e não o consumo. No caso da frequente entrada no crédito rotativo, as pessoas pagarão três ou quatro vezes o valor do produto. Miguel de Oliveira, diretor da Anefac, resume bem a situação: "A pessoa que não consegue pagar a fatura e precisa parcelar, ou entrar no rotativo, na verdade está financiando a dívida do cartão de crédito com outro tipo de crédito. $\mathrm{O}$ problema é que essa dívida não tem fim. As pessoas acabam não se dando conta dos juros que terão que pagar” (DCI, Bl, 20.8.2014).

Como as pessoas têm dificuldades em imaginar que o sistema tenha sido tão grosseiramente deformado, apresentamos a tabela de juros (Quadro 3) cobrados pelo Banco Santander. O "Custo Efetivo Total" do crédito rotativo no Santander, por exemplo, informado em tabela enviada aos clientes, é de 633,21\%.

Obviamente, com essas taxas de juros, as pessoas, ao fazer uma compra a crédito, gastam mais com os juros do que com o próprio valor do produto adquirido. Costuma-se apresentar apenas a taxa de endividamento das famílias, próxima de $30 \%$, o que não é informação suficiente, pois aqui as famílias não só se endividam muito, como se endividam muito comprando pouco. A conta é evidente: em termos práticos, pagam quase o dobro, às vezes mais. Dito de outra forma, compram a metade do que o dinheiro deles poderia comprar, se fosse à vista. Isso porque a compra à vista já inclui os lucros de intermediação comercial.

Não é o imposto o vilão, ainda que o peso dominante dos impostos indiretos só piore a situação: é o desvio da capacidade de compra para o pagamento de juros. As famílias estão gastando muito mais, resultado do nível elevado de emprego e da elevação do poder aquisitivo da base da sociedade, mas os juros esterilizam a capacidade de dinamização da economia pela demanda que esses gastos poderiam representar. Um dos principais vetores de dinamização da economia se vê travado. Gerou-se uma economia de atravessadores financeiros. Prejudi- 
cam as famílias que precisam dos bens e serviços, e indiretamente as empresas efetivamente produtoras que veem os seus estoques parados. Perde-se boa parte do impacto de dinamização econômica das políticas redistributivas. O crédito consignado ajuda, mas atinge apenas $23,5 \%$ do crédito para consumo (DCI, 2014), e também se situa na faixa de $25 \%$ a $30 \%$ de juros, o que aparece como baixo apenas pelo nível exorbitante que atingem as outras formas de crédito.

Quadro 3 - Tabela de juros cobrados pelo Banco Santander

\begin{tabular}{|c|c|c|c|c|c|c|c|}
\hline $\begin{array}{l}\text { Operação } \\
\text { de Crédito }\end{array}$ & $\begin{array}{c}\text { Taxa de } \\
\text { Juros ao } \\
\text { Mês } \\
(\%)\end{array}$ & $\begin{array}{c}\text { Taxa de } \\
\text { Juros } \\
\text { ao Ano } \\
(\%)\end{array}$ & $\begin{array}{l}\text { IOF Adi- } \\
\text { cional } \\
(\%)\end{array}$ & $\begin{array}{l}\text { IOF } \\
(\%)\end{array}$ & $\begin{array}{c}\text { Seguro } \\
\text { Presta- } \\
\text {-mista } \\
(\%) \\
\text { (se con- } \\
\text {-tratado) }\end{array}$ & $\begin{array}{l}\text { Tarifa } \\
(\mathrm{R} \$)\end{array}$ & $\begin{array}{c}\text { Custo } \\
\text { Efetivo } \\
\text { Total } \\
\text { ao Ano } \\
(\%)\end{array}$ \\
\hline Crédito Rotativo & 16,99 & 557,33 & 0,38 & 0,1230 & & - & 633,21 \\
\hline $\begin{array}{l}\text { Compras } \\
\text { Parceladas } \\
\text { c/ Juros }\end{array}$ & 1,90 & 25,34 & 0,38 & 0,1230 & & - & 30,07 \\
\hline Saque à vista & 19,99 & 790,71 & 0,38 & 0,1230 & & 15,00 & 997,96 \\
\hline $\begin{array}{l}\text { Parcelamento } \\
\text { da Fatura }\end{array}$ & 9,29 & 190,37 & 0,38 & 0,1230 & 3,50 & - & 324,80 \\
\hline SuperCrédito & - & - & - & - & - & - & - \\
\hline Total Parcelado & 6,50 & 112,90 & 0,38 & 0,1230 & 4,50 & - & 171,85 \\
\hline
\end{tabular}

Fonte: Mailing do Banco Santander para clientes, Brasil.

Para os Parcelamentos (Parcelamento da Fatura e Total Parcelado) o cálculo é realizado com base no plano com menor quantidade de parcelas e no valor do limite total disponível para a respectiva operação, informados nesta fatura.

Para o Saque à Vista, se disponível, o cálculo é realizado com base no valor do limite total disponível, informado nesta fatura.

Para o Crédito Rotativo (Pagamento Parcial) o cálculo é realizado com base na diferença entre o valor total desta fatura e o valor do Pagamento Mínimo, informados nesta fatura.

\section{Os juros para pessoa jurídica}

As taxas de juros para pessoa jurídica não ficam atrás. $\mathrm{O}$ estudo da Anefac apresenta uma taxa praticada média de $50,06 \%$ ao ano, sendo $24,16 \%$ para capital de giro, $34,80 \%$ para desconto de duplicatas, e $100,76 \%$ para conta garantida. Ninguém em sã consciência consegue desenvolver atividades produtivas, criar uma empresa, enfrentar o tempo de entrada no mercado e de equilíbrio de contas pagando esse tipo de juros. Aqui, é o investimento privado que é diretamente atingido.

A atividade bancária pode ser perfeitamente útil ao financiar iniciativas econômicas que darão retorno. Mas isso implica o banco utilizar o dinheiro dos depósitos (além, naturalmente, da alavancagem) para fomentar iniciativas empresariais, cujo resultado dará legítimo lucro ao investidor, permitindo também restituir o empréstimo. A atividade básica de um banco, que seria de reunir 
poupanças de depositantes para transformá-las em financiamento de atividades econômicas, saiu do horizonte de atividade desses bancos. A economia, travada do lado da demanda com o tipo de crédito ao consumo visto acima, tanto nos bancos como nos crediários, vê-se portanto igualmente travada do lado do financiamento ao produtor. Prejudica-se assim tanto a demanda como o investimento, os dois motores da economia.

Quadro 4 - Taxa de juros para pessoa jurídica

\begin{tabular}{|c|c|c|c|c|c|c|}
\hline \multirow{2}{*}{$\begin{array}{l}\text { Linha de } \\
\text { Crédito }\end{array}$} & \multicolumn{2}{|c|}{ Maio 2014} & \multicolumn{2}{|c|}{ Junho 2014} & \multirow{2}{*}{$\begin{array}{c}\text { Variação } \\
\%\end{array}$} & \multirow{2}{*}{$\begin{array}{c}\text { Var. Pontos } \\
\text { Percentuais } \\
\text { ao Mês }\end{array}$} \\
\hline & Taxa Mês & Taxa Ano & Taxa Mês & Taxa Ano & & \\
\hline Capital de Giro & $1,84 \%$ & $24,46 \%$ & $1,82 \%$ & $24,16 \%$ & $-1.09 \%$ & $-0,02$ \\
\hline $\begin{array}{l}\text { Desconto de Dupli- } \\
\text { catas }\end{array}$ & $2,48 \%$ & $34,17 \%$ & $2,52 \%$ & $34,80 \%$ & $1,61 \%$ & 0,04 \\
\hline Conta garantida & $5,92 \%$ & $99,40 \%$ & $5,98 \%$ & $100,76 \%$ & $1,01 \%$ & 0,06 \\
\hline Taxa Média & $3,41 \%$ & $49,54 \%$ & $3,44 \%$ & $50,06 \%$ & $0,88 \%$ & 0,03 \\
\hline
\end{tabular}

Fonte: Anefac, 2014. Disponível em: <http://www.anefac.com.br/uploads/arquivos/2014715153 114381.pdf>.

As regras do jogo aqui se deformam profundamente. As grandes corporações transnacionais passam a ter vantagens comparadas impressionantes ao poder se financiar do exterior com taxas de juros tipicamente cinco ou seis vezes menores do que os seus concorrentes nacionais. Muitas empresas nacionais podem encontrar financiamentos com taxas que poderiam ser consideradas normais, por exemplo pelo BNDES e outros bancos oficiais, mas sem a capilaridade que permita irrigar a imensa massa de pequenas e médias empresas dispersas no país. Não é demais lembrar que na Alemanha $60 \%$ das poupanças são administradas por pequenas caixas de poupança locais, que irrigam generosamente as pequenas iniciativas econômicas. A Polônia, que segundo o Economist melhor enfrentou a crise na Europa, tem 470 bancos cooperativos, que financiam atividades da economia real. Um dos principais economistas do país, J. Balcerek, comenta ironicamente que "o nosso atraso bancário nos salvou da crise".

\section{Os juros sobre a dívida pública}

Uma terceira deformação resulta do imenso dreno sobre recursos públicos através da dívida pública. Se arredondarmos o nosso PIB para 4,8 trilhões de reais, $1 \%$ do PIB são 48 bilhões. Quando gastamos 5\% do PIB para pagar os juros da dívida pública, significa que estamos transferindo, essencialmente para os bancos donos da dívida, e por sua vez a um pequeno grupo de afortunados, quase 250 bilhões de reais ao ano, que deveriam financiar investimentos públicos, políticas sociais e semelhantes. Para a sociedade, trata-se aqui de uma esterilização da poupança. Para os bancos, é muito cômodo, pois em vez de terem 
de identificar bons empresários e fomentar investimentos, tendo de avaliar os projetos, enfim, fazer a lição de casa, aplicam em títulos públicos, com rentabilidade elevada, liquidez total, segurança absoluta, dinheiro em caixa, por assim dizer, e rendendo muito.

Quadro 5 - Resultado fiscal do setor público

\begin{tabular}{c|c|c|c|c}
\hline$\%$ do PIB & & & & \\
\hline Ano & Res.Primário & Juros & Res.Nominal & Selic \\
\hline 2002 & 3,2 & $-7,7$ & $-4,5$ & 19,2 \\
\hline 2003 & 3,3 & $-8,5$ & $-5,2$ & 23,5 \\
\hline 2004 & 3,7 & $-6,6$ & $-2,9$ & 16,4 \\
\hline 2005 & 3,8 & $-7,4$ & $-3,6$ & 19,1 \\
\hline 2006 & 3,2 & $-6,8$ & $-3,6$ & 15,3 \\
\hline 2007 & 3,3 & $-6,1$ & $-2,8$ & 12,0 \\
\hline 2008 & 3,4 & $-5,5$ & $-2,0$ & 12,5 \\
\hline 2009 & 2,0 & $-5,3$ & $-3,3$ & 10,1 \\
\hline 2010 & 2,7 & $-5,2$ & $-2,5$ & 9,9 \\
\hline 2011 & 3,1 & $-5,7$ & $-2,6$ & 11,8 \\
\hline 2012 & 2,4 & $-4,9$ & $-2,5$ & 8,6 \\
\hline 2013 & 1,9 & $-5,1$ & $-3,3$ & 8,3 \\
\hline 2014 prev & 1,5 & $-6,0$ & $-4,5$ & 11,0 \\
\hline & & & &
\end{tabular}

Fonte: Banco Central, 2014, previsão Amir Khair.

Comenta Amir Khair (Comunicação pessoal):

Neste ano (2015) com taxa de juros média maior que em 2014, incidindo sobre uma dívida mais elevada pode causar uma despesa próxima de $7 \%$ do PIB e, com resultado primário de $1,2 \%$ do PIB, que é a meta traçada pela nova equipe, o déficit fiscal seria de $6 \%$ do PIB, ou seja, mais endividamento e mais despesas com juros, em verdadeiro ciclo vicioso.

O efeito aqui é duplamente pernicioso: por uma lado, porque com a rentabilidade assegurada com simples aplicação na dívida pública, os bancos deixam de buscar o fomento da economia, fazem aplicações financeiras em papéis do governo, em vez de irrigar as atividades econômicas com empréstimos; por outro, muitas empresas produtivas, em vez de fazer mais investimentos, aplicam também os seus excedentes em títulos do governo. A máquina econômica torna-se assim refém de um sistema que rende para os que aplicam, mas não para os que investem na economia real. E para o governo, é até cômodo, pois é mais fácil se endividar do que fazer a reforma tributária tão necessária.

\section{Uma deformação sistêmica}

A Tabela 1 mostra que a taxa real de juros para pessoa física (descontada 
a inflação) cobrada pelo HSBC no Brasil é de 63,42\%, quando é de 6,60\% no mesmo banco para a mesma linha de crédito no Reino Unido. Para o Santander, as cifras correspondentes são 55,74\% e 10,81\%. Para o Citibank são 55,74\% e $7,28 \%$. O Itaú cobra sólidos $63,5 \%$. Para pessoa jurídica, área vital porque se trataria de fomento a atividades produtivas, a situação é igualmente absurda. Para pessoa jurídica, o HSBC, por exemplo, cobra 40,36\% no Brasil, e 7,86 no Reino Unido (Ipea, 2009)

Tabela 1 - Taxa anual real de juros total* sobre empréstimos pessoais em instituições bancárias em países selecionados na primeira semana de abril de 2009

\begin{tabular}{c|c|c}
\hline Instituição & País & Juro real ( em\%) \\
\hline \multirow{2}{*}{ HSBC } & Reino Unido & 6,60 \\
\cline { 2 - 3 } & Brasil & 63,42 \\
\hline \multirow{2}{*}{ Santander } & Espanha & 10,81 \\
\cline { 2 - 3 } & Brasil & 55,74 \\
\hline \multirow{2}{*}{ Citibank } & EUA & 7,28 \\
\cline { 2 - 3 } & Brasil & 60,84 \\
\hline Banco do Brasil & Brasil & 25,05 \\
\hline Itaú & Brasil & 63,25 \\
\hline
\end{tabular}

Fonte: Dados fornecidos pelas instituições bancárias para os juros e OCDE e BCB para inflação nos selecionados e no Brasil.

*Juros adicionados aos serviços administrativos, riscos de inadimplência, margem de lucro e tributação.

Comenta o estudo do Ipea (2009):

Para empréstimos à pessoa física, o diferencial chega a ser quase 10 vezes mais elevado para o brasileiro em relação ao crédito equivalente no exterior. Para as pessoas jurídicas, os diferenciais também são dignos de atenção, sendo prejudiciais para o Brasil. Para empréstimos à pessoa jurídica, a diferença de custo é menor, mas, mesmo assim, é mais de 4 vezes maior para o brasileiro.

Enfrentamos aqui, portanto, uma deformação estrutural do nosso sistema de intermediação financeira. Não há grande mistério no processo: a financeirização mundial, com as suas diversas formas de organização segundo os países e as legislações, adquiriu aqui formas diferentes de travar a economia, dimensão nacional de uma deformação hoje planetária.

A nossa constituição, no artigo 170, define como princípios da ordem econômica e financeira, entre outros, a função social da propriedade (III) e a livre concorrência (IV). O artigo 173, no parágrafo $4^{\circ}$, estipula que “a lei reprimirá o abuso do poder econômico que vise à dominação dos mercados, à eliminação da concorrência e ao aumento arbitrário dos lucros". O parágrafo 5 é ainda mais explícito: “A lei, sem prejuízo da responsabilidade individual dos dirigentes da pessoa jurídica, estabelecerá a responsabilidade desta, sujeitando-a às punições compatíveis com sua natureza, nos atos praticados contra a ordem econômica e 
financeira e contra a economia popular". Cartel é crime. Lucro exorbitante sem contribuição correspondente produtiva será "reprimido pela lei" com "punições compatíveis".

O resultado prático é uma deformação sistêmica do conjunto da economia, que trava a demanda do lado do consumo, fragiliza o investimento, e reduz a capacidade do governo de financiar infraestruturas e políticas sociais. Se acrescentarmos a deformação do nosso sistema tributário, baseado essencialmente em impostos indiretos (embutidos nos preços), com frágil incidência sobre a renda e o patrimônio, temos aqui o quadro completo de uma economia prejudicada nos seus alicerces, que avança sem dúvida, mas carregando um peso morto cada vez menos sustentável.

\section{A dimensão internacional}

O dreno sobre as atividades produtivas, tanto do lado do consumo como do lado do investimento, é planetário. Faz parte de uma máquina internacional que desde a liberalização da regulação financeira com os governos Reagan e Thatcher no início dos anos 1980, até a liquidação do principal sistema de regulação, o Glass-Steagall Act, por Clinton em 2009, gerou um vale-tudo internacional.

A dimensão internacional tornou-se hoje mais documentada a partir da crise de 2008. O próprio descalabro gerado e o travamento da economia mundial levaram a que fossem levantados os dados básicos das finanças internacionais, que curiosamente sempre escaparam do "International Financial Statistics" do FMI. Apresentamos em outros estudos o detalhe de cada uma das novas pesquisas que surgiram, e apenas resumimos aqui o seus principais resultados, para facilitar uma visão de conjunto.

O Instituto Federal Suíço de Pesquisa Tecnológica (ETH na sigla alemã) constatou que 147 grupos controlam $40 \%$ do mundo corporativo do planeta, sendo $75 \%$ deles instituições financeiras. Pertencem na sua quase totalidade aos países ricos, essencialmente Europa ocidental e Estados Unidos. (ETH, 2011).

O Tax Justice Network, com pesquisa coordenada por James Henry, apresenta o estoque de capitais aplicados em paraísos fiscais, da ordem de 21 a 32 trilhões de dólares, para um PIB mundial da ordem de 70 trilhões. Estamos falando de quase um terço a metade do PIB mundial. A economia do planeta está fora do alcance de qualquer regulação, e controlada por intermediários, não por produtores. O rentismo impera, e é apresentado como desafio na reunião do G20 em novembro de 2014 (TJN, 2012).

O dossiê produzido pelo Economist sobre os paraísos fiscais ("The missing \$ 20 trillion") arredonda o estoque para 20 trilhões, mas mostra que são geridos pelos principais bancos do planeta, não em ilhas paradisíacas, mas essencialmente por bancos dos Estados Unidos e da Inglaterra (Economist, 2013).

As pesquisas do ICIJ (International Consortium of Investigative Journalists) têm chegado a inúmeros nomes de empresas e donos de fortunas, com 
detalhes de instruções e movimentações, progressivamente divulgados à medida que trabalham os imensos arquivos recebidos. Em novembro de 2014 publicaram o gigantesco esquema de evasão fiscal das multinacionais, usando o paraíso fiscal que se tornou Luxemburgo. São apresentados em detalhe os montantes de evasão por parte dos bancos Itaú e Bradesco (ICIJ, 2014; Rodrigues, 2014).

O estudo de Joshua Schneyder, sistematizando dados da Reuters, mostra que dezesseis grupos comerciais internacionais controlam o essencial da intermediação das commodities planetárias (grãos, energia, minerais), a maior parte com sedes em paraísos fiscais (Genebra em particular), criando o atual quadro de especulação financeira-comercial sobre os produtos que constituem o sangue da economia mundial. Lembremos que os derivativos dessa economia especulativa (outstanding derivatives) ultrapassam 600 trilhões de dólares, para um PIB mundial de 70 trilhões (BIS, 2013) (Schneyer, 2013)

O Crédit Suisse divulga a análise das grandes fortunas mundiais apresentando a concentração da propriedade de 223 trilhões de dólares acumulados (patrimônio acumulado, não a renda anual), sendo que basicamente $1 \%$ dos mais afortunados possui cerca de $50 \%$ da riqueza acumulada no planeta.

Temos assim um sistema planetário deformado, e o Brasil é uma peça apenas na alimentação do processo mundial de concentração de capital acumulado por intermediários financeiros e comerciais. Não temos estudos suficientes nem pressão política correspondente para ter o detalhe de como funciona esta engrenagem no Brasil. No entanto, dois estudos nos trazem ordens de grandeza.

O estudo mencionado do Tax Justice Network desdobra algumas cifras de estoques de capital em paraísos fiscais por regiões. No caso do Brasil, encontramos como ordem de grandeza 519,5 bilhões de dólares, o que representa cerca de $25 \%$ do PIB brasileiro (primeira linha, quinta coluna de cifras da Tabela 2).

Assim, o Brasil não está isolado, nesse sistema planetário, nem é particularmente corrupto. Mas o conjunto criado é sim profundamente corrompido. Os dados para o Brasil, 519,5 bilhões de dólares em termos de capitais offshore, são de toda forma impressionantes, ocupamos o quarto lugar no mundo. Esses recursos deveriam pagar os impostos, que permitiriam ampliar investimentos públicos, e deveriam ser aplicados em fomento da economia onde foram gerados.

Um segundo estudo particularmente interessante é do Global Financial Integrity (GFI, 2014), coordenado por Dev Kar, Brasil: fuga de capitais, fluxos ilícitos e as crises macroeconômicas, 1960-2012. Trata-se de uma sangria de recursos por evasão, estimada em cerca de 100 bilhões de reais por ano entre 2010 e 2012 (cerca de $2 \%$ do PIB). São recursos que por sua vez irão alimentar em boa parte o estoque de mais de um trilhão de reais em paraísos fiscais visto acima. Segundo o relatório, "o governo deve fazer muito mais para combater tanto o subfaturamento de exportações como o superfaturamento de importações, adotando ativamente medidas dissuasivas adicionais em vez de punições 
retroativas". Trata-se aqui, dominantemente, das empresas multinacionais. Kofi Annan considera que esse mecanismo drena cerca de 38 bilhões de dólares por ano das economias africanas. O mecanismo é conhecido como mispricing, ou trade misinvoicing (GFI, 2014).

Tabela 2 - Fluxos não registrados de capital, ativos off-shore e ganhos off-shore 1997-2010

América Latina e Região do Caribe

Dívida externa ajusta para alterações monetárias, reescalonamento e atrasados

Bilhões de $\$$ de 2000, Nominal e real

40 países na região -33 com dados

\begin{tabular}{|c|c|c|c|c|c|c|c|c|c|c|}
\hline & \multirow{2}{*}{ Country } & \multicolumn{2}{|c|}{ Original Outflows } & $\begin{array}{c}\text { Offshore } \\
\text { Earnings } \\
\text { (S\$B) }\end{array}$ & \multicolumn{2}{|c|}{$\begin{array}{c}\text { CF/GNI CF/Sources } \\
\text { Period Merinas }\end{array}$} & \multirow{2}{*}{$\begin{array}{l}\text { Fligth Stock } \\
\text { (\$B 2010) } \\
\text { Nominal }\end{array}$} & \multirow{2}{*}{$\begin{array}{c}\begin{array}{c}\text { External } \\
\text { Debt }\end{array} \\
\text { (\$B 2010) } \\
\text { Nominal }\end{array}$} & \multirow{2}{*}{$\begin{array}{l}\text { CF Stock } \\
\text { Ext.Debt. } \\
\qquad \%\end{array}$} & \multirow{2}{*}{$\begin{array}{c}\text { Offshore } \\
\text { Earing } \\
\% \\
\text { Outtlows } \\
\%\end{array}$} \\
\hline & & Nom \$ & $\$ 2000)$ & (\$2000) & $\%$ & $\%$ & & & & \\
\hline $1970-2010$ & Brazil & $\$ 345.0$ & $\$ 362.6$ & $\$ 247.3$ & $1.7 \%$ & $43 \%$ & $\$ 519.5$ & $\$ 324.5$ & $160 \%$ & $68 \%$ \\
\hline $1970-2010$ & Argentina & $\$ 213.9$ & $\$ 259.3$ & 272.8 & $3.4 \%$ & $68 \%$ & $\$ 399.1$ & $\$ 129.6$ & $308 \%$ & $105 \%$ \\
\hline $1970-2010$ & México & $\$ 223.7$ & $\$ 263.5$ & $\$ 299.1$ & $1.8 \%$ & $36 \%$ & $\$ 417.4$ & $\$ 186.4$ & 224 & $113 \%$ \\
\hline $1970-2010$ & Venezuela & $\$ 269.1$ & $\$ 278.2$ & $\$ 202.0$ & $5.7 \%$ & $82 \%$ & $\$ 405.8$ & $\$ 55.7$ & $728 \%$ & $73 \%$ \\
\hline \multirow[t]{2}{*}{$1970-2010$} & All Others (29) & $\$ 205.1$ & $\$ 211.9$ & $\$ 169.1$ & $1.7 \%$ & $41.5 \%$ & $\$ 316$. & $\$ 317$ & $100 \%$ & \\
\hline & Lac Total & $\$ 1,254.8$ & $\$ 1,375.5$ & $\$ 1,190.3$ & $2.5 \%$ & $51 \%$ & $\$ 2,058.3$ & $\$ 1,013.4$ & $203 \%$ & $87 \%$ \\
\hline
\end{tabular}

Fonte: Disponível em: <http://www.taxjustice.net/cms/upload/pdf/Appendix\%203\%20-\%202012 \%20Price\%20 f\%20Offshore\%20pt\%201\%20-\%20pp\%201-59.pdf>. Source: World Bank IMF/ UN / central bank/CIA(data); JSH analysis @JSH2012.

Adjusted for Currency of Debt; 75\% Reinvestment Rate; Ave Yielt - \$US 6 mos CD rate.

\section{Resgatando o controle}

É importante antes de tudo entendermos os limites da atuação de um governo. No plano internacional, enquanto existir a tolerância de fato, por parte das elites americanas e europeias, dos paraísos fiscais, inclusive nos próprios Estados Unidos como é o caso do estado de Delaware, e na Europa como é o caso de Luxemburgo e da Suíça, dificilmente haverá qualquer possibilidade de controle real. A evasão fiscal torna-se demasiado simples, e a possibilidade de localizar os capitais ilegais muito reduzida. A ordem pode, no entanto, ser bastante melhorada no controle das saídas, do sub e do sobrefaturamento e semelhantes. O relatório da GFI (2014) aponta essas possibilidades e reconhece fortes avanços do Brasil nos últimos anos. No plano internacional, surge finalmente o BEPS (Base Erosion and Profit Shifting), endossado por quarenta países que representam $90 \%$ do PIB mundial, início de redução do sistema planetário de evasão fiscal pelas empresas transnacionais (OCDE, 2014).

No plano interno, as medidas não podem ser diretas. A Anefac $(2014$, p.8) deixa claras as limitações de um sistema que é formalmente regido pelo direito privado: 
Destacamos que as taxas de juros são livres e as mesmas são estipuladas pela própria instituição financeira não existindo assim qualquer controle de preços ou tetos pelos valores cobrados. A única obrigatoriedade que a instituição financeira tem é informar ao cliente quais as taxas que lhe serão cobradas caso recorra a qualquer tipo de crédito.

Naturalmente, como se trata de um cartel, o tomador de crédito não tem opção. As recomendações da Anefac são muito simples: "Se possível adie suas compras para juntar o dinheiro e comprar o mesmo à vista evitando os juros". Ou seja, não use o crédito. Isso recomendado pela Associação dos Executivas de Finanças, Administração e Contabilidade é impressionante.

Mas o governo tem armas poderosas. A primeira é retomar a redução progressiva da taxa Selic, o que obrigaria os bancos a procurarem aplicações alternativas, voltando a irrigar iniciativas de empreendedores, e reduzindo o vazamento dos recursos públicos para os bancos. A segunda é reduzir as taxas de juros ao tomador final na rede de bancos públicos, conforme foi experimentado em 2013, mas persistindo dessa vez na dinâmica. É a melhor forma de introduzir mecanismos de mercado no sistema de intermediação financeira, contribuindo para fragilizar o cartel e obrigando-o a reduzir os juros estratosféricos: o tomador final voltaria a ter opções.

A terceira consiste no resgate de um mínimo de equilíbrio tributário: não se trata de aumentar os impostos, mas de racionalizar a sua incidência. A pesquisa do Inesc $(2014$, p.21) mostra que “a tributação sobre o patrimônio é quase irrelevante no Brasil, pois equivale a 1,31\% do PIB, representando apenas $3,7 \%$ da arrecadação tributária de 2011. Em alguns países do capitalismo central, os impostos sobre o patrimônio representam mais de $10 \%$ da arrecadação tributária, como, por exemplo, Canadá (10\%), Japão (10,3\%), Coreia $(11,8 \%)$, Grã-Bretanha $(11,9 \%)$ e EUA $(12,15)$ ". Se acrescentarmos a baixa incidência do imposto sobre a renda, e o fato de os impostos indiretos representarem $56 \%$ da arrecadação, temos no conjunto uma situação que clama por mudanças. Convém destacar que a carga tributária é muito regressiva no Brasil, pois está concentrada em tributos indiretos e cumulativos que oneram mais os/as trabalhadores/as e os mais pobres, uma vez que mais da metade da arrecadação provém de tributos que incidem sobre bens e serviços, havendo baixa tributação sobre a renda e o patrimônio. Segundo informações extraídas da Pesquisa de Orçamento Familiar (POF) de 2008/2009 pelo Ipea, estima-se que 10\% das famílias mais pobres do Brasil destinam 32\% da renda disponível para o pagamento de tributos, enquanto $10 \%$ das famílias mais ricas gastam $21 \%$ da renda em tributos. (Inesc, 2014, p.6)

A quarta consiste naturalmente em dinamizar um conjunto de pesquisas sobre os fluxos financeiros internos, e disponibilizá-las amplamente, de maneira a gerar uma transparência maior nessa área em que as pessoas simplesmente não se orientam. Para gerar a força política capaz de reduzir o grau de cartelização, 
reintroduzindo mecanismos de mercado e transformando o sistema de intermediação financeira, é preciso ter uma população informada. Um das coisas mais impressionantes para essa área vital para o desenvolvimento do país é o profundo silêncio não só da mídia, mas também da academia e dos institutos de pesquisa, sobre o processo escandaloso de deformação da economia pelo sistema financeiro.

Quadro 6 - Incidência de impostos no Brasil - 2011

\begin{tabular}{c|c|c}
\hline & \% da arrecadação & $\%$ do PIB \\
\hline Consumo & $55,7 \%$ & $19,7 \%$ \\
\hline Renda & $30,5 \%$ & $10,8 \%$ \\
\hline Patrimônio & $3,7 \%$ & $1,3 \%$ \\
\hline Outros & $10,1 \%$ & $3,6 \%$ \\
\hline Total & $100 \%$ & $35,4 \%$ \\
\hline
\end{tabular}

Fonte: Inesc - Implicações do sistema tributário brasileiro, set. 2014, (parte da Tab.1 p. 13).

Façam-se as contas da maneira que for: o fato é que a economia brasileira está sendo sangrada por intermediários que pouco ou nada produzem. Se somarmos as taxas de juros à pessoa física, o custo dos crediários, os juros à pessoa jurídica, o dreno através da dívida pública e a evasão fiscal por meio dos paraísos fiscais e das transferências ilícitas, temos uma deformação estrutural dos processos produtivos. Tentar dinamizar a economia enquanto arrastamos esse entulho especulativo preso nos pés fica muito difícil. Há mais mazelas na nossa economia, mas aqui estamos falando de uma massa gigantesca de recursos, e que são necessários ao país. É tempo do próprio mundo empresarial - aquele que efetivamente produz riquezas - acordar para os desequilíbrios, e colocar as responsabilidades onde realmente estão. O resgate organizado do uso produtivo dos nossos recursos é essencial.

10 de fevereiro de 2015

\section{Referências}

ABECS - Associação Brasileira de Empresas de Cartões de Crédito e Serviços. Disponível em: <http://www.abecs.org.br/indicadores-de-mercado>.

ANEFAC. Relatório sobre juros, 2014, tabelas das páginas 2, 3 e 5 Disponível em: <http://www.anefac.com.br/uploads/arquivos/2014715153114381.pdf>.

BANCO CENTRAL - Histórico da taxa de juros - Selic - 2014. Disponível em : <http://www.bcb.gov.br/?COPOMJUROS>.

BIS QUARTERLY REVIEW. June 2013, p.3. Disponível em: <http://www.bis.org/ $\mathrm{publ} / \mathrm{qtrpdf} / \mathrm{r} \_\mathrm{qt1306.pdf>}$.

DCI - Metade do consumo é financiada por cartões - 20 de agosto de 2014, p.B1. 
DOWBOR, L. Os estranhos caminhos do nosso dinheiro. São Paulo: Editora Fundação Perseu Abramo, 2014. Disponível em: <http://dowbor.org/blog/wp-content/ uploads/2012/06/13-Descaminhos-do-dinheiro-p\%C3\%BAblico-16-julho.doc>.

ECONOMIST. The rise of Black Rock. Dec. $7^{\text {th }}$ 2013. Disponível em:, <http://www. economist.com/news/leaders/21591174-25-years-blackrock-has-become-worlds-biggest-investor-its-dominance-problem $>$.

ECONOMIST. The missing $\$ 20$ trillion. Special Report on Offshore Finance, Feb. $16^{\text {th }}$ 2013.

ETH - Swiss Federal Institute of Technology, 2011. Disponível em: <http://dowbor. org/2012/02/a-rede-do-poder-corporativo-mundial-7.html>.

FURTADO, C. Para onde caminhamos? Jornal do Brasil, 14 nov. 2004. Disponível em: <http://www.centrocelsofurtado.org.br/arquivos/image/201411191728100. Dossier\%20CF\%2020\%20nov\%202014\%20ArtigoJBNovembro2004.pdf>.

GFI. Brasil: fuga de capitais - Global Financial Integrity, Set. 2014. Disponível em: <http://www.gfintegrity.org/wp-content/uploads/2014/09/Brasil-Fuga-de-Capitais-os-Fluxos-Il\%C3\%ADcitos-e-as-Crises-Macroecon\%C3\%B4micas-1960-2012.pdf>.

HENRY, J. Tax Justice Network. The Price of off-shore revisited-Disponível em: <http:// www.taxjustice.net/cms/front_content.php?idcat=148> [Os dados sobre o Brasil estão no Appendix III, (1) p.23, Disponível em: <http://www.taxjustice.net/cms/upload/ pdf/Appendix\%203\%20-\%202012\%20Price\%20of\%20Offshore $\% 20$ pt $\% 201 \% 20-\% 20$ pp\%201-59.pdf>. Ver também no site da TJN a atualização de junho 2014 <http:// www.taxjustice.net/wp-content/uploads/2014/06/The-Price-of-Offshore-Revisited-notes-2014.pdf>].

ICIJ - International Consortium of Investigative Journalists, 2013. Disponível em: <www.icij.org/offshore/how-icijs-project-team-analyzed-offshore-files $>$.

ICIJ - Luxemburg Tax Files - November 2014. Disponível em: <http://www.theguardian.com/business/2014/nov/05/-sp-luxembourg-tax-files-tax-avoidance-industrial-scale> [para os dados em português referentes ao Itaú e ao Bradesco, ver artigo de Fernando Rodrigues, Folha de S.Paulo, 5 de nov. 2014. Disponível em: <http://wwwl. folha.uol.com.br/mercado/2014/11/1543572-itau-e-bradesco-economizam-r-200-mi-em-impostos-com-operacoes-em-luxemburgo.shtml>.]

INESC. As implicações do sistema tributário brasileiro na desigualdade de renda - setembro de 2014. Disponível em: <http://www.inesc.org.br/biblioteca/textos/as-implicacoes-do-sistema-tributario-nas-desigualdades-de-renda/publicacao $>$.

IPEA. Transformações na indústria bancária brasileira e o cenário de crise - Comunicado da Presidência, Abril de 2009, p.15. Disponível em: <http://www.ipea.gov.br/ sites/000/2/pdf/09_04_07_ComunicaPresi_20_Bancos.pdf>.

KHAIR, A. A borda da cachoeira. O Estado de S. Paulo, $1^{\circ}$ fev. 2015. Disponível em: <http://economia.estadao.com.br/noticias/geral,a-borda-da-cachoeira-imp-,1627819>.

OCDE - ICIJ. BEPS: Base Erosion and Profit Shifting. 2014. Disponível em: <http:// publicintegrity.us4.list-managel $. \mathrm{com} /$ track/click? u=8dc6eceed67f7f012462d0bl2\&i $\mathrm{d}=\mathrm{f} 388 \mathrm{dcl}$ 436\&e $=\mathrm{d} 256201 \mathrm{ac5}>$. 
RODRIGUES, F. Folha de S. Paulo. 5 nov. 2014. Disponível em: <http://wwwl.folha.uol.com.br/mercado/2014/11/1543572-itau-e-bradesco-economizam-r-200-mi-em-impostos-com-operacoes-em-luxemburgo.shtml>

SCHNEYER, J. Commodity Traders: the Trillion Dollars Club. Disponível em: <http://dowbor.org/2013/09/joshua-schneyer-corrected-commodity-traders-the-trillion-dollar-club-setembro-201319p.html> ou <www.reuters.com/assets / print?aid=USTRE79R4S320111028>.

TJN - Tax Justice Network, 2012. The Price of off-shore revisited. Disponível em: <http://www.taxjustice.net/cms/front_content.php?idcat=148 Os dados sobre o Brasil estão no Appendix III, (1) p. 23 http://www.taxjustice.net/cms/upload/pdf/ Appendix\%203\%20-\%202012\%20Price\%20of\%20Offshore $\% 20 p t \% 201 \% 20-\% 20 p p \% 20$ 1-59.pdf>.

VITALI, S.; GLATTFELDER, J. B.; BATTISTON, S. ETH, The Network, of Global Corporate Control. Disponível em: <http://arxiv.org/pdf/1107.5728.pdf>.

RESUMO - A financeirização está no centro dos debates econômicos, porque aprofunda a desigualdade e sobretudo porque trava o desenvolvimento. Este último aspecto é alvo de numerosos estudos internacionais, e aqui abordamos o mecanismo como se manifesta no Brasil. Basicamente, os crediários, cartões de crédito e juros bancários para pessoa física travam a demanda, pois tipicamente o comprador paga o dobro do valor do produto, endivida-se muito comprando pouco, o que esteriliza o impacto de dinamização da economia pela demanda. Os juros elevados para pessoa jurídica travam por sua vez o investimento, isto porque o empresário efetivamente produtivo já enfrenta a fragilidade da demanda. E a taxa Selic elevada, ao provocar a transferência de centenas de bilhões dos nosso impostos para os bancos e outros aplicadores financeiros, trava a capacidade de o Estado expandir políticas sociais e infraestruturas. Essa dinâmica no contexto de uma carga tributária que onera desproporcionalmente o consumo popular, e de um sistema de evasão dos impostos através em particular dos paraísos fiscais, gera um dreno insustentável de recursos que explica que tenhamos uma alta taxa de emprego e um PIB que estagna. As recomendações vão no sentido de uma reforma financeira, e não do ajuste fiscal atualmente proposto.

PALAVRAS-CHAVE: Bancos, Juros, Financeirização, Paraísos fiscais, PIB.

ABSTRACT - Inequality is exploding. Oxfam is spreading the word and the figures, Crédit Suisse shows us where the wealth is going, Thomas Piketty shows how it works in rich countries. The money has to come from somewhere: this paper presents the Brazilian equivalent of the overall financialization system. The important initiative to promote inclusion, jobs and unrequited transfers to the poor during the Lula and Dilma administrations has produced excellent results. But the financial system of income and wealth concentration has caught up with the initiatives and is stalling the Brazilian economy through huge interest rates on consumers, investors and the public debt. See the me- 
chanism and the numbers in this short report. All figures are referred to primary sources through links, and easy to check.

KEYWORDS: Banks, Interest rates, Financialization, Tax havens, GDP.

Ladislau Dowbor é doutor em Ciências Econômicas pela Escola Central de Planejamento e Estatística de Varsóvia, professor titular da PUC de São Paulo e consultor de diversas agências das Nações Unidas. É autor de $A$ reprodução social, O mosaico partido, Tecnologias do conbecimento: os desafios da educação, Democracia econômica, todos pela Editora Vozes, além de O que acontece com o trabalho? (Senac), e co-organizador da coletânea Economia social no Brasil (Senac), Estranhos caminhos do nosso dinheiro (Fundação Perseu Abramo) Seus trabalhos sobre planejamento econômico e social estão disponíveis no site http://dowbor.org

@-ldowbor@uol.com.br / @-ladislau@dowbor.org

Recebido em 12.2.2015 e aceito em 20.2.2015.

I Pontifícia Universidade Católica de São Paulo, São Paulo/SP, Brasil. 